13. Medvedkov A.A. The Kets ethnos and its «feeding landscape»: ecologo-geographical and social-and-ecological problems in conditions of globalization and changing climate // Geography, Environment, Sustainability. 2013. № 3. Pp. 108-118.

УДК 551.5, 911.3

A.A. Medvedkov ${ }^{1}$

\title{
TRANSFORMATION OF «FEEDING LANDSCAPES» AND TRADITIONAL CULTURE OF INDIGENOUS SIBERIAN POPULATIONS (ON THE EXAMPLE OF THE KETS) UNDER GLOBALIZATION AND CLIMATE CHANGE
}

\begin{abstract}
This article discloses the analysis of «feeding landscapes» and their natural ecological resources, which are the basis of life support systems of indigenous populations. We consider all following risks and changes of their traditional lifestyle. By the example of one of ethnic groups we demonstrate coping strategies and adaptations to climatic and environmental changes with due consideration of ethno-cultural specifics.
\end{abstract}

Key words: "feeding landscape», traditional knowledge, climate change, indigenous peoples, life support systems, Kets ethnicity, Siberia.

Introduction. At present, the processes of globalization and global warming make a quite pronounced impact on the lives of indigenous people in the northern regions of the country, e.g., Nenets, Chukchi, Kets, etc. For them, fishing, hunting, herding, and natural landscapes are not only a source of livelihood resource, but also part of their traditional culture. Climate change (impact on productivity of «feeding landscapes,» increase of natural hazards, etc.), social factors (alcoholism, loss of the Kets language, poaching, etc.), and new worldviews that have emerged and have been growing in the post-perestroika period are the main causes that threaten the well-being, livelihoods, and the preservation of cultural traditions of the Kets ethnos and its identity. The issues of developing appropriate measures and strategies for adaptation of the traditional economy and way of life of Kets and other ethnic groups to a changing climate and market economy become extremely relevant.

The Kets is one of the smaller nations of Central Siberia that consists of dispersed groups mainly in the middle and lower reaches of the Yenisei River, as well as in the lower reaches of the Podkamennaya Tunguska River (Yenisei Ostiak, Yenisei). They became known in the XVIIth century through the first Russian Yenisei explorers. The modern name of the people - Kets - appeared in the 1920s. This is not a self-ethnic name; it was imposed superiorly. This was due to the fact that the Khunt (with whom Ket were in contact in the upper reaches of the Taz River) and the Kets immediate neighbors - the Selkup - continued to be called Ostyak. The total number of the Kets is close to 1,200 people. The traditional territory of their settlement is the Turukhansk and Evenk Municipal Districts of the Krasnoyarsk Kray (Fig. 1).

In terms of the linguistic and national characteristics, the Kets are classified as the most unique ethnic group not only in Russia, but in the world. The uniqueness of the Kets is evident in the fact that their language has a distinctive formation that has no analogues among the neighboring nations. The Kets language (now the relic) is the last of the living languages of the big family of the Yenisei people. The cultural-economic type of Kets (resident anglers and hunters) continue to exist. Modern Kets still fish, hunt elk and forest reindeer, gather mushrooms, berries, and nuts, and procure furs (sable, squirrel).

${ }^{1}$ Lomonosov Moscow State University, Faculty of Geography, Russia, 119991, Moscow, GSP-1, 1 Leninskiye Gory, senior researcher, PhD in Geography; e-mail: a-medvedkov@bk.ru. 


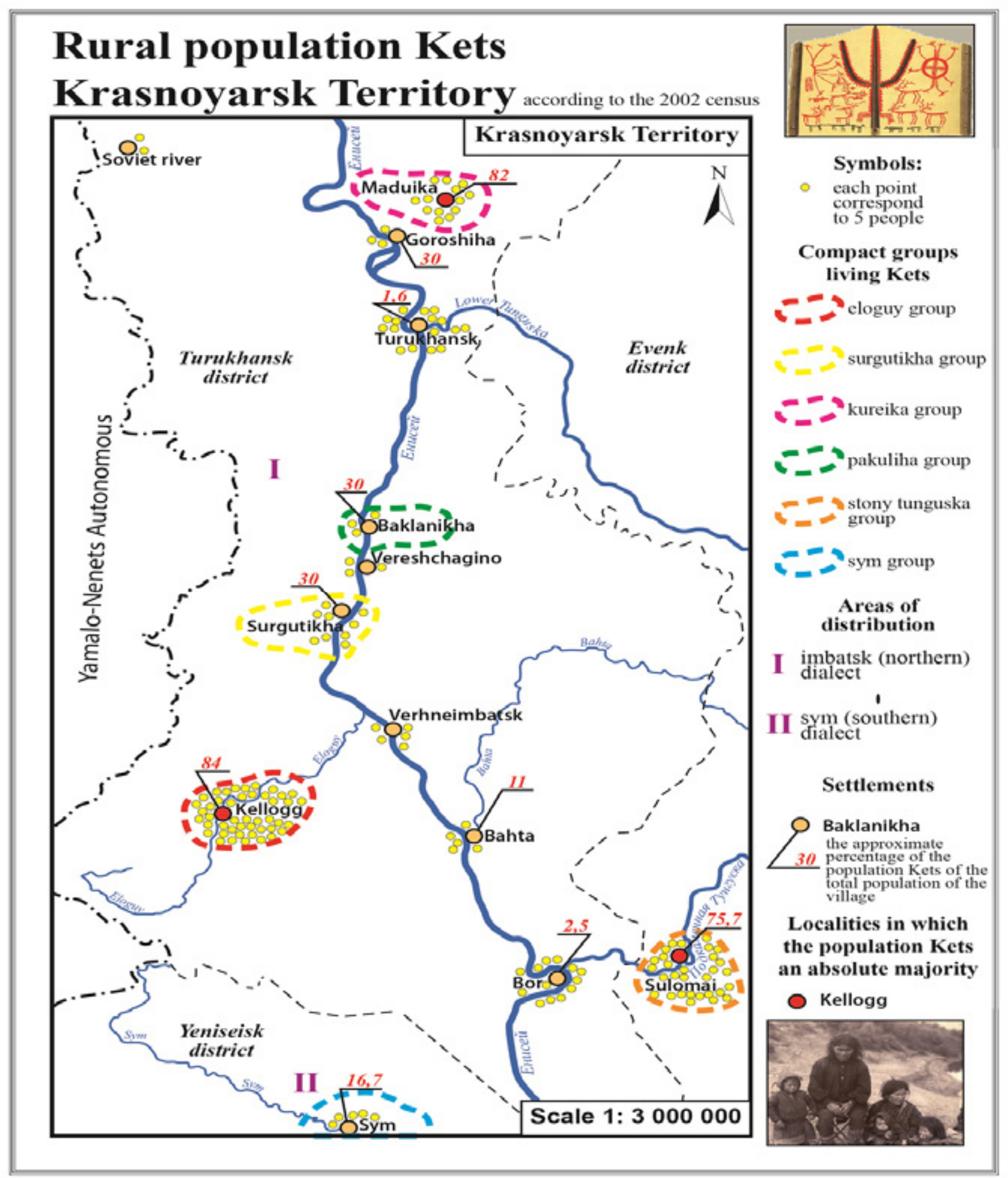

Fig. 1. Settlement and the numbers of the Kets in the Krasnoyarsk Kray. Compiled by the author (Medvedkov, 2013)

Materials and methods. Hydro-meteorological data of the local weather stations and the general Russian reference sources were processed to identify fluctuations of the temperature and precipitation parameters in the Central-Siberian region in the XXth century. The monitoring data based on the surveys of the Kets families were used to assess changes of environmental parameters and the fodder value of the natural systems of the middle taiga (at the level of complex natural boundaries) under climate warming. The traditional economy is «rigidly» tied to the landscape and all the stressful situations in the natural complex are immediately reflected in 
their self-sufficiency and social well-being, which suggests a high degree of reliability of the information we have collected. The total number of households surveyed is 25 (the number of hunting areas within the hunting community Sulomai); 57 respondents represent about half of the residents of the village Sulomai. All respondents pointed the declining yields of berries (especially blueberry and bilberry), and during dry summer - of rowan and cranberry; there are fewer mushrooms. One of the examples identified during the Sulomai survey is especially revealing: a woman noted that prior to the 1990s, she could gather and hand over 30 pails of cranberries and now she can hardly gather 2 pails. There are similar examples for other berries. The respondents noted an increase in the number of «sick» (rotten) berries, increasing the probability of its abscission in the last 15-20 years. They associate the increase in the number of bears attacks on people with low berries yields.

The Kets families that have their own hunting areas transferred through inheritance have important information about the dynamics of the production of any type of animal or berry crop over rather long period, i.e., a few decades. Many Kets have their own environmental calendars that mark important hydro-meteorological and phenological events. In the absence of the established system of monitoring in the taiga zone of Central Siberia such data have an important scientific value for identification of the response of natural and environmental resources of the taiga and the traditional economy of the indigenous population to climate warming. The author has also conducted field surveys (over 5 field seasons since 2008) during which he recorded the yield and percentage of flowering berry and estimated resources of commercial plants in different types of natural systems.

Results and discussion. Preservation of Ket Ethnic Group Ethocultural Traditions. The main problems of the Kets are alcoholism, unemployment, unfavorable demographic situation (increased mortality in middle age, the younger generation leaving for cities in more populated areas), and the loss of the Kets language. Penetration of Baptism plays a certain positive role in the fight against alcoholism. Having become Baptists, the Kets stop drinking alcohol, become more economically and socially active. However, with acceptance of the evangelical faith, the Kets have to pay $1 / 10$ of their meager incomes: fish, furs, or cash. These processes lead to the transformation of some elements of the traditional worldview of their pagan religious system, culture, and ritual practice. The Orthodox Christianity «combined» as a rule, with the traditional beliefs and cults, never behaved as aggressively as evangelism.

Along with the gradual disappearance of traditions and the assimilation processes in relation to Kets, the Kets language is dissapearing too. In elementary school, the Kets language is now taught and a primeir and other tutorials have been created. However, this is not sufficient to revive the language of indigenous people and this does not always find understanding and support even among the Kets themselves. Today, education remains the only area of the use of the Kets language. The students of senior classes, who studied the Kets language in the first three classes of elementary school, do not remember its basics. This is due to three main reasons. First, in the vast majority of settlements, there are only elementary schools, while students can continue their studies only in the regional centers and in larger towns where the Kets language is not included in the curricula and there is lack of qualified teachers on the subject. Therefore, unfortunately, the effectiveness of teaching the Kets language in school is extremely low. Given the specificity of the region and of its transport and remoteness, there are good prospects for the development of distance education.

Second, in daily communication the younger generation of Kets do not speak their language in their national settlements with parents, friends, and peers.

Third, the attempts to revive the Kets language are not always understood, even among the members of the ethnic group, not to mention the district-level authorities. For a long time, the language has been transmitted only from parents to children. In the period from the 1920 s to present, the Kets language has not been widely used. Today's young generation and their parents do not know their language, perhaps only a few words. According to various estimates, only $15 \%$ of 
the aboriginal population has command of the Kets language. It indicates the widespread destruction of the process of natural language transmission within families from parents to children. Some even claim that the Kets language is not needed for communicate either for themselves or for their children. We have identified such trends through surveys of the local population even in mono-ethnic villages.

Life Support Systems in a Changing Climate. In the Central Yenisei region, the modern climate change has been registered since the 1980s, which is clearly seen in Fig. 2. Analysis indicates that all 4 stations have observed a positive trend of changes in the annual air temperature. The annual average temperature grew by $1-2^{\circ} \mathrm{C}$ and greater compared with the previous period of cooling. Winter became warmer; spring and fall are longer than in 1959-1970. However, periodically, there are years with shorter summers.

Warming of the climate, characterized by frequent mild winters and longer springs and falls, affects feed resources of the taiga. Famine years became more frequent. Thus, in 1997 and 1998, in the Central Siberian Reserve (one of the largest reserves of the planet with the size of the territory of Lebanon or Jamaica), blueberry, huckleberry, bilberry, honeysuckle, and red and black currant were almost completely absent. Their meager harvests were also in 1999; a similar situation persists to the present day, which is confirmed by the data of monitoring studies in the Reserve and surveys of local residents. The locals say that in the years with cool summers and mild winters, there are few places where pine nuts can be found, despite the widespread availability of cedar pine in the dark taiga. Such changes are especially important to the traditional nature management of the Kets since they do not have a welldeveloped subsidiary farming.

There are marked changes in the habitat of tick-borne encephalitis; the tick is now detected around the $63^{\circ} \mathrm{N}$. The ixodes ticks (Ixodes persulcatus), over the past 25 years, have moved $250 \mathrm{~km}$ to the north and now occupy the middle taiga subzone of our research area. The likelihood of tickborne infections has increased. The activity of the ticks has been especially strong in the last 10 years (Medvedkov, 2015). According to our surveys, it affects the population of the local villages Vorogovo, Bor, Sulomai, Kuzmovka, and other settlements; there, people have been frequently requesting vaccination against tick-borne encephalitis.

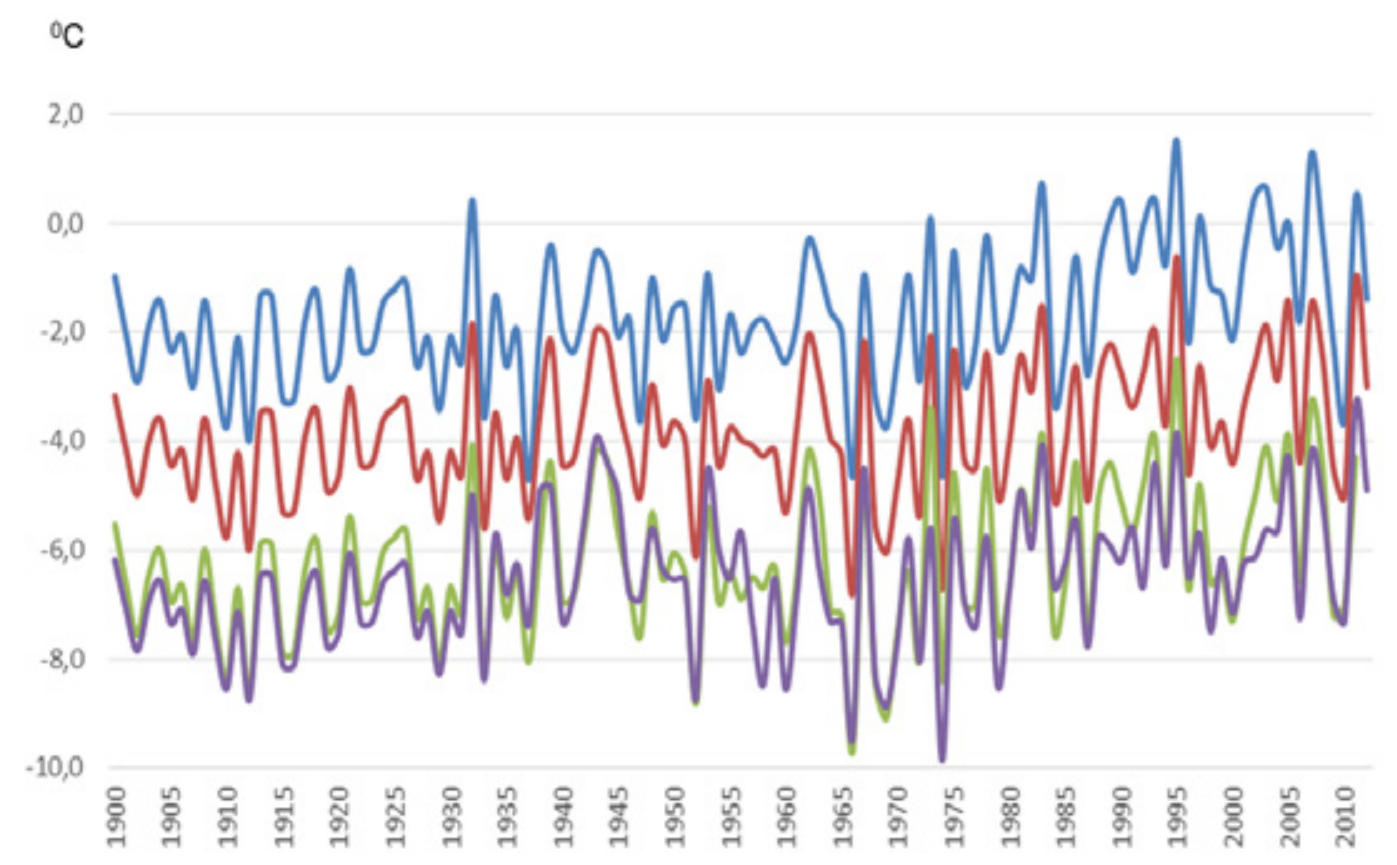

Fig. 2. Fluctuations in mean annual air temperature in the Central Siberia in $1900-2012$. Compiled by the author 
Kurums is a type of the permafrost landscapes of the Yenisei Siberia that was the least stable in the era of global warming. Within kurums, even on slopes with poor heat-supply, the goltsy ice thawed, small depressions formed, and cold streams disappeared. They were overgrown with lichen, shrubs, and scattered trees. Pika, which plays an important role in the diet of sable, is abandoning kurums. These processes are promoted by late spring frosts and the loss of underground water resources at the base of kurums (Medvedkov, 2013).

Instances of hydrological anomalies also increased. A sharp warming in early spring and existing frozen impervious layer cause high and even catostrophic flooding that coincides with melting and drifting of ice. For example, in the snowless winter of 2001, an ice dam $30 \mathrm{~m}$ high formed, which caused serious flooding. As a result, the Kets settlement on the Podkamennaya Tunguska River was completely destroyed. The old-timers do not recall floods of such magnitude. Now, due to the increased frequency of floods of ice-dammed origin, the Kets are forced to move their homes to the watershed areas. After 2001, the regional services has been conducting blasts of ice dams.

Conclusion. We can assume that the trophic pyramid of the middle taiga has been significantly disrupted due to global warming and the growth of climate instability. Naturally, these changes adversely affect the traditional natural resource use of the Kets who cannot meet their growing material needs. The issue of development of appropriate measures and strategies is becoming increasingly relevant; they should become the leading adaptation basis of the traditional economy and way of life of the local population to a changing climate.

The reduced life-support functions of the «feeding landscape» (in the terminology of L.N. Gumilev) requires a focus on the comprehensive development of the traditional forms of natural resource use and their diversification, support of their resource and manufacturing base, and the organization of processing of raw materials and products. At the present stage, the Kets subsidiary farms are weak, though, they could become an important sector of food selfsufficiency of the local population. It is possible to establish plantations growing valuable species of mushrooms, berries, and herbs to increase the volume of commodity production. This would create additional incentives for the traditional Kets natural resource use. The creation of local plantations of medicinal plants would contribute to the formation of the region's production of environmentally friendly raw materials for medicines. These resources are available in the Kets TTU, where gathering of medicinal plants was carried out in the Soviet time. The volume of such procurement has been identified for some species of medicinal plants. Some Siberian regions have a successful experience with the use of non-timber forest resources.

It seems that in the context of global warming and growth of climate instability, a close relationship between the traditional economy of indigenous peoples, the natural resources, and environmental, and geographical factors of the environment becomes even more pronounced.

Acknowledgement. The study was supported by Russian Foundation for Basic Research (project project 15-06-02279a, 16-35-00327- mol_a) and supported by the Council for Grants under President of Russia (project $M K-7614.2015 . \overline{5}$ ).

\section{REFERENCES}

1. Medvedkov A.A. The Kets ethnos and its «feeding landscape»: ecological-geographical and socio-and-ecological problems under globalization and changing climate // Geography, Environment, Sustainability, 2013, № 3 (V. 6), Pp. 108-118.

2. Medvedkov A.A. Geoenvironmental response of the Yenisei Siberia mid-taiga landscapes to global warming during late XX-early XXI centuries, 2015, № 7 (V. 42), Pp. 922-931. 